Case Report

\title{
A Case of Syrian Child with Cerebral Infarction as an Extraintestinal Manifestation of Ulcerative Colitis
}

\author{
Riham Salloum, ${ }^{1}$ Nawras Alhalabi $\mathbb{D}^{1},{ }^{1}$ and Mohamad Anas Almidani ${ }^{1,2}$ \\ ${ }^{1}$ Faculty of Medicine, Syrian Private University, Damascus, Syria \\ ${ }^{2}$ Department of Neurology, Damascus Hospital, Damascus, Syria \\ Correspondence should be addressed to Nawras Alhalabi; nawras@me.com
}

Received 3 January 2019; Revised 6 February 2019; Accepted 13 February 2019; Published 26 February 2019

Academic Editor: Hirotada Akiho

Copyright (c) 2019 Riham Salloum et al. This is an open access article distributed under the Creative Commons Attribution License, which permits unrestricted use, distribution, and reproduction in any medium, provided the original work is properly cited.

\begin{abstract}
Thromboembolic complications are rare but well-recognized manifestation of ulcerative colitis, especially because of their associated high mortality. We report a case of a Syrian child admitted to Damascus Hospital with a one-day complaint of sudden onset of numbness followed by weakness in the left lower and upper limbs, right mouth angle deviation, and loss of sphincters' control. Earlier, she was diagnosed with ulcerative colitis and treated with immunosuppressants. CT and MRI scans revealed focal infarction around the M2-M3 segments of the right middle cerebral artery; she was treated with Aspirin. On discharge, she had significant improved neurological examination and was able to walk. Subsequent proctocolectomy was performed. We highlight the importance of thromboembolism in ulcerative colitis as there is paucity in the literature regarding its management and its symptoms may be overlooked especially in high-load central hospitals. We conducted a brief literature search and summarized findings of similar reported cases.
\end{abstract}

\section{Introduction}

Extraintestinal manifestations of idiopathic inflammatory bowel disease (IBD) have been reported in $25 \%$ to $36 \%$ of patients [1]. Common manifestations include sacroiliitis $(14 \%)$ and peripheral arthritis (10.7\%), while rare manifestations include ocular (8\%), mucocutaneous (2.7\%), and vascular (2\%) [2].

Neurologic manifestations in IBD appear to be more common than previously estimated with a reported incidence of cerebrovascular complications in $0.12 \%$ to $4 \%$ of all patients with IBD $[3,4]$. Generally, it occurs as a postoperative complication and found more in Crohn's disease than ulcerative colitis (UC) [5]. Thromboembolic complications of UC are reported at an incidence of only $1.2 \%-7.5 \%$, but are well recognized because of their associated high mortality [6-9] which occurs in $60 \%$ of cases [4].

We report a rare case of a Syrian child who was suffered a cerebrovascular accident (CVA) as a complication of ulcerative colitis. To the best of our knowledge, this is the first documented case in Syria.

\section{Case Presentation}

A 15-year-old Syrian female was admitted to the hospital on November 2016 with a one-day complaint of sudden onset of numbness in the left lower and upper limbs, followed by weakness in the same areas, right mouth angle deviation, and loss of sphincters' control. She did not experience headache, nausea, vomiting, convulsions, or coma.

Eight months earlier, she developed massive rectal bleeding, colonoscopy was performed, and the patient was diagnosed with ulcerative colitis (UC). She was treated with mesalazine 1 gram three times daily, azathioprine 50 milligram daily, prednisolone 40 milligram daily, and cefuroxime 500 milligram tab twice daily for a week.

She has no history of smoking, alcohol abuse, or illicit drug use. She did not report any suspected allergies and she has no other history of hypertension, diabetes mellitus, cardiac, rheumatological, or hematological disease.

On examination, her vital signs are blood pressure 100/60 mmhg, Pulse $110 /$ minute, respiratory rate $36 /$ minute, and temperature $37.5^{\circ} \mathrm{C}$. General examination revealed conjunctival pallor and pitting edema in the left lower limb and 


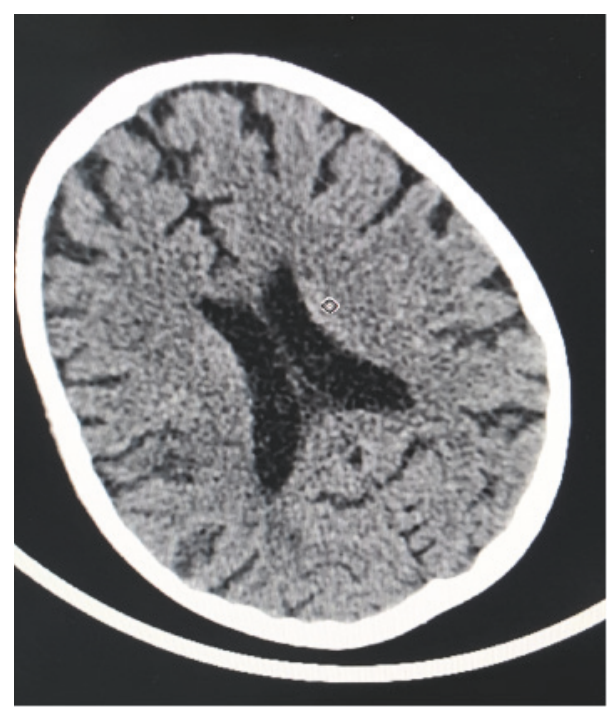

FIgure 1: Patient CT scan showing showed small hypodensity foci situated in the cortical and subcortical area in right partial lobe.

purple stretch marks extends on the whole lower limbs till the sacrum.

On neurological examination, there was no impaired consciousness and the patient was awake and alert. Cranial nerves exam was only significant for left facial nerve palsy. Motor examination showed 5/5 strength in the right upper and lower limbs, 3/5 left upper limb, and 0/5 left lower limb; there was also hypotonia on the left limbs and normal tone on the right limbs without any atrophy. Reflexes examinations scored $2 / 4$ for the right limbs (normal) and $1 / 4$ for the left limbs (hyporeflexia). Right toes showed planter flexion and absence of the flexion for the left toes. No cerebellar abnormalities were noted in the right side; cerebellar exam was not performed on the left side due to limbs weakness. She scored 10 on National Institutes of Health Stroke Scale (NIHSS). Sensory examination revealed loss superficial and deep sensations on the left side and normal sensations on the right side. Other systematic examinations, including cardiac, respiratory, and gastrointestinal systems, were all normal.

Investigations including blood tests showed evidence of pancytopenia (hemoglobin $4.4 \mathrm{~g} / \mathrm{dL}$, platelets: $66 \mathrm{x} 1000 / \mathrm{mm} 3$ dropped to $3 \times 1000 / \mathrm{mm} 3$ after in two days of admission, WBCs: $1.4 \mathrm{x} 1000 / \mathrm{mm} 3$ with $35 \%$ neutrocytes, 61\% lymphocytes, $3 \%$ monocytes, and $1 \%$ eosinophils); urinalysis values were within normal ranges. Thrombophilic and immunological screening including homocysteine, factor V Leiden, protein $\mathrm{C}$, protein $\mathrm{S}$, antithrombin, lupus anticoagulant factor, and antiphospholipid antibodies were all insignificant.

An emergency computerized tomography (CT) scan (Figure 1) showed small hypodensity foci situated in the cortical and subcortical area in right partial lobe. Magnetic resonance imaging (MRI) (Figure 2) showed cortical and subcortical areas in the right temporoparietal fossa with high signal on T2 and FALIR studies. T1 study showed isointense foci in the cortical and subcortical area in the posterior part of the parietal lobe extending deeply through the posterior horn of the right lateral ventricle. Based on these findings, the accident is complicated with focal infarction around the M2M3 segments of the right middle cerebral artery. Aspirin $162 \mathrm{mg}$ was given upon these findings and the prednisolone treatment was continued.

Cardiac echocardiogram and carotid arteries Doppler ultrasound study were both normal. The patient did not complain of any symptoms related to her UC when she had the CVA, which indicates that the UC was not in active stage.

On December 2016, the patient was able to walk and her neurological examination dramatically improved (NIHSS: 0); she was then discharged and referred to physical therapy. On January 2017, the patient suffered from overt rectal bleeding, she was admitted again to the hospital, and proctocolectomy was performed.

A written informed consent was obtained from the patient before writing this report, Syrian Private University and Damascus Hospital Ethical Committee approved the report, and both are available upon request.

\section{Discussion}

Increased coagulability and thrombosis due to IBD were first described in 1936 [29]. Intestinal inflammation may lead to increased risk for thrombosis through several pathways: activation of coagulation cascade, decreasing anticoagulant activity, inducing hypofibrinolysis, malabsorption, and hypercatabolism with vitamin deficiencies [4]. Most patients with IBD do not have demonstrable specific coagulation defects [30]. Dehydration, immobility, sepsis, surgery, and corticosteroid therapy are also risk factor for thrombosis in IBD patients [31]. The precise mechanism of these factors remains unclear. Arterial thrombosis particularly strokes may be considered a rare condition [17] but with high morbidity and mortality [32-34].

Males and females may be equally affected which correlates with previously reported cases. The cerebral vascular involvement seems more frequent among younger IBD patients [4]. Conventional CT scan or MRI is used to define the cerebral affected areas. At this moment, no guidelines are available for the treatment of cerebral thrombosis and strokes in IBD [17].

By reviewing previous literature, Schneiderman et al. were the first to report similar case with thrombosis of the left internal carotid artery (ICA) and occlusion of the left distal basilar artery in two separate patients with UC respectively [26]. The youngest patient reported was a 1-year-old girl with UC, who was complicated with bacterial endocarditis and subsequent infarctions of both middle cerebral arteries (MCA) [27].

We have conducted a brief literature search and summarized cases reported on Cerebral Arterial Thrombosis associated with UC using modified version of Katsanos et al. [35] table (Table 1).

About half of the patients were on corticosteroid treatment and more than one-third of them were being treated with 5-aminosalicylic acid (5-ASA) at the time of the cerebrovascular event [35]. The predominant neurological symptom on admission in most of the case reports was left 


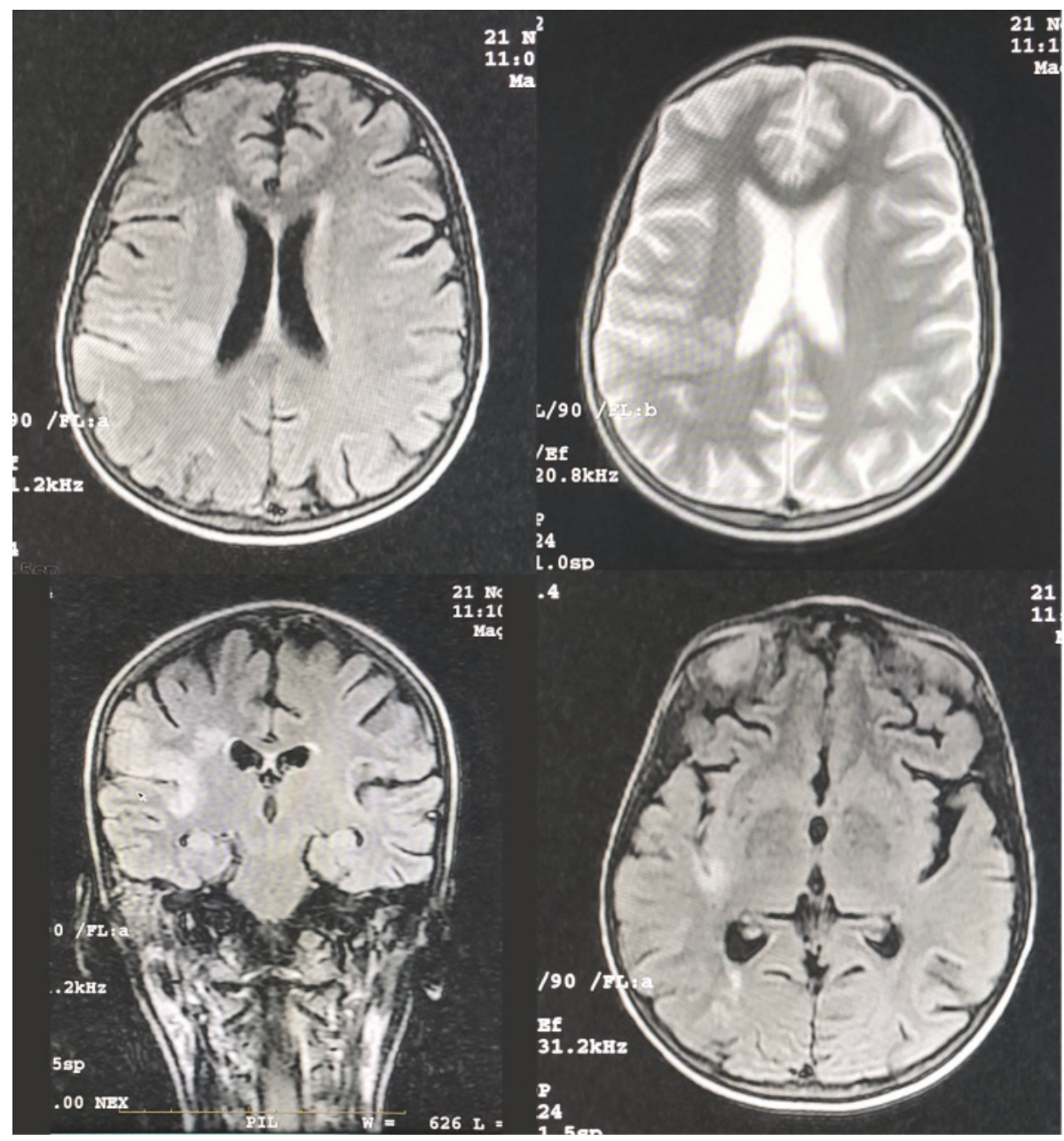

FIGURE 2: Patient MRI showing cortical and subcortical areas in the right temporoparietal fossa with high signal on T2 and FALIR studies, in addition to isointense foci in the cortical and subcortical area in the posterior part of the parietal lobe extending deeply through the posterior horn of the right lateral ventricle on T1 study.

or right sided hemiparesis; our patient was also admitted with left hemiparesis as the main complication. In addition, the right or left MCA was the most frequent sites of cerebral arterial thromboembolism depicted on imaging studies similar to our patient that manifested with cerebral arterial thromboembolism around the M2-M3 segments of the right MCA as confirmed by imaging studies [35]. As previously reported, the risk of arterial thromboembolic events may be increased in patients with active disease [4], although our patient did not have an active disease by the time of CVA.

Thrombocytosis and anemia were the most commonly observed potential risk factors for cerebral arterial infarction in the laboratory analysis [35], although there is no sufficient evidence supporting the theory of solitary thrombocytosis causing thromboembolic phenomena [26]. Our patient contrary presented with pancytopenia which may be due to immunosuppressants given [36].

Our patient did not have a demonstrable specific coagulation defects, in comparison; hyperhomocysteinemia [4] and other acquired deficiencies of antithrombin III and protein $S$ have previously been reported in similar cases
[30, 35]. Finally, smoking and severe dehydration have been mentioned in only two cases contrary to our patient.

Our patient received Aspirin as a treatment after she was diagnosed with the cerebrovascular accident. She had improved neurological examination on discharge and she was able to walk; she was then discharged and referred to physical therapy, although as reported in previous cases also most of the patients also recovered either without any or with minor neurological deficits; either they received anticoagulation or antiplatelet treatment or not [35] (Table 1).

Clinical experience treatment of arterial ischemic cerebral lesions in patients with IBD is very limited due to lack of enough trials [37]. More studies are required to clarify the correlation between IBD and the thrombophilias and to evaluate the role of anticoagulant therapy and proctocolectomy in the management of these patients. Similarly, there is also lack of steady evidence and official guidelines for stroke management in both children and adults with IBD comorbidity. Both American Heart Association and European Stroke Organization guidelines for stroke management and prevention in the general population are currently 


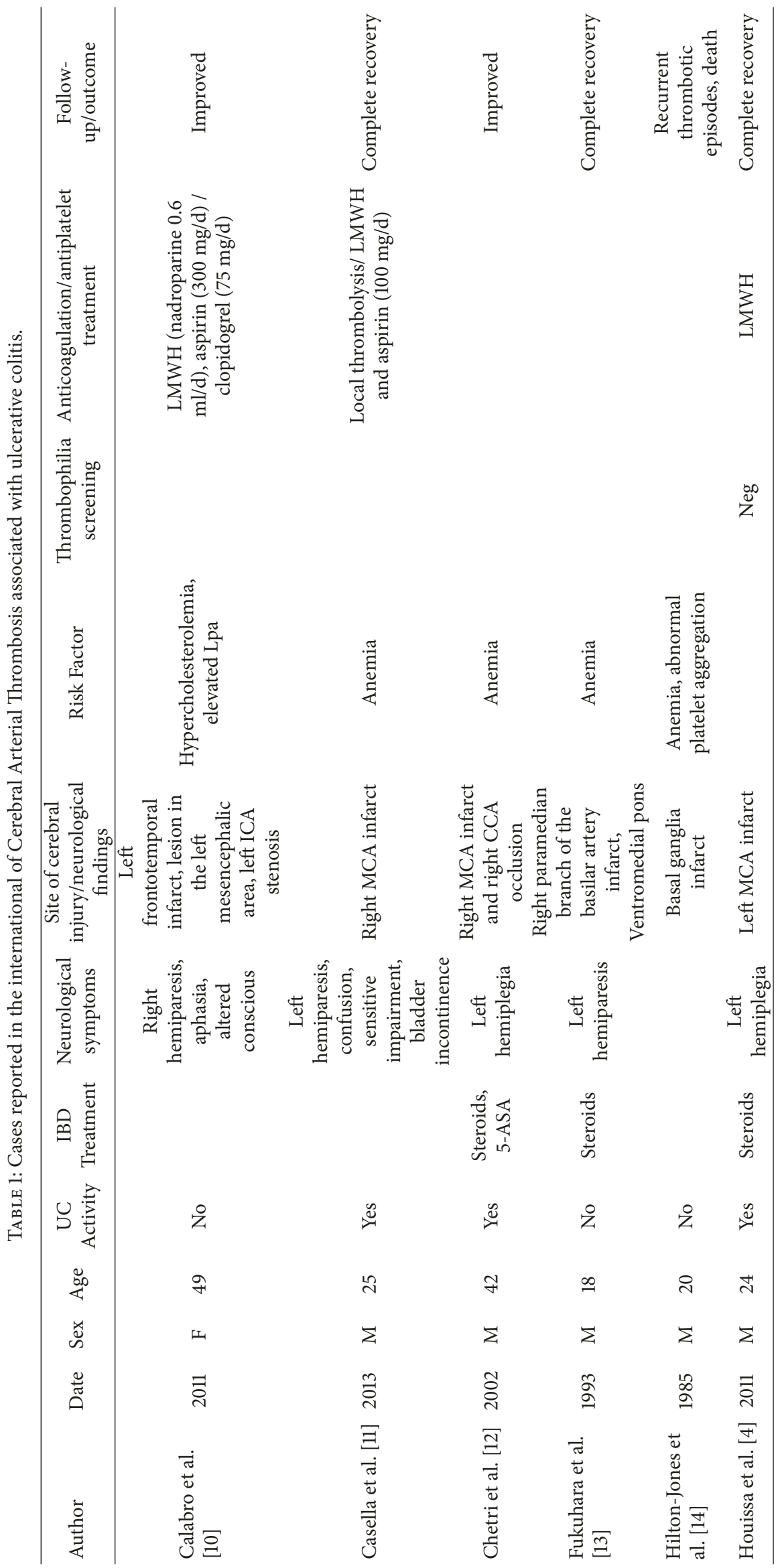




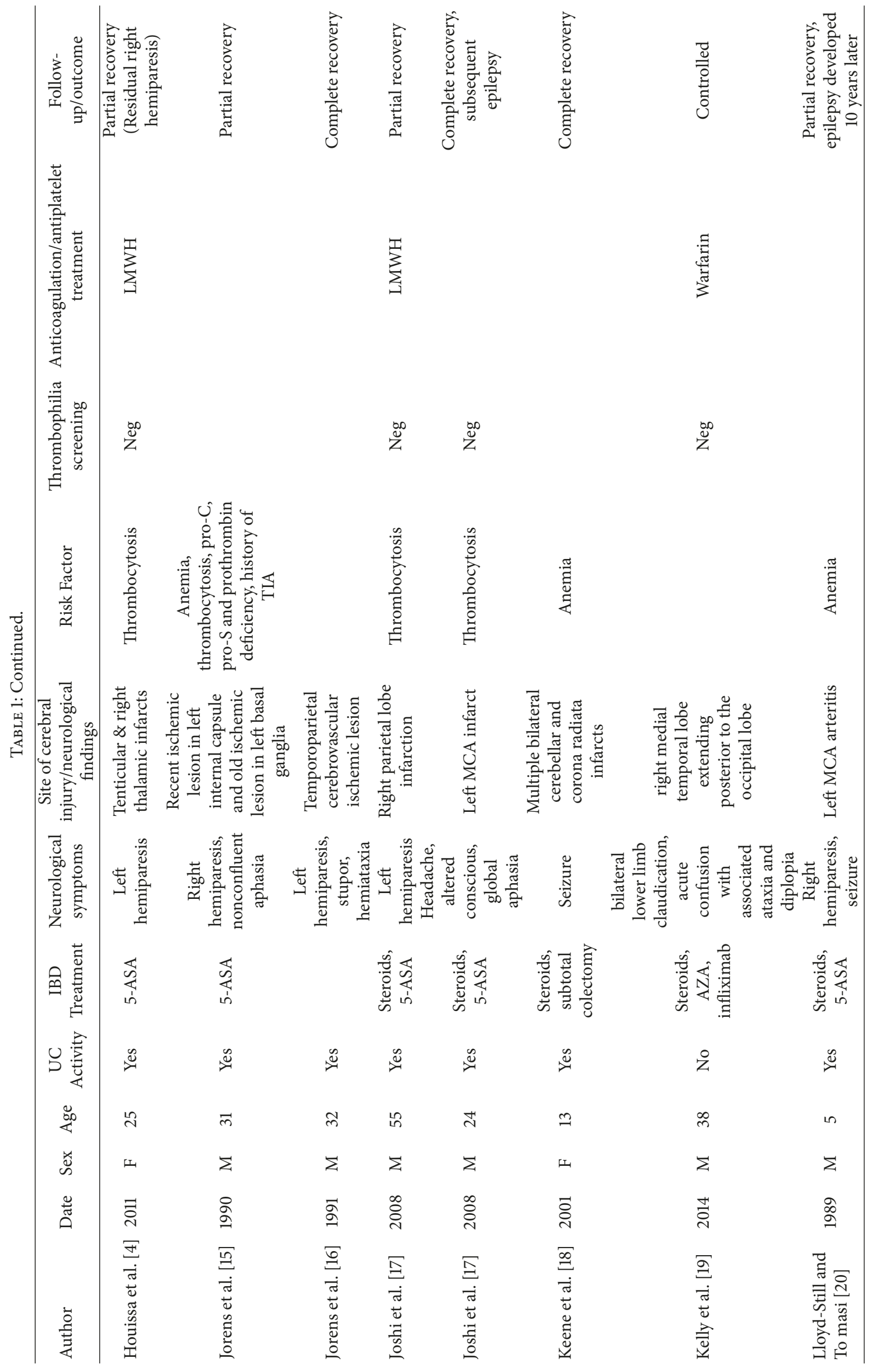




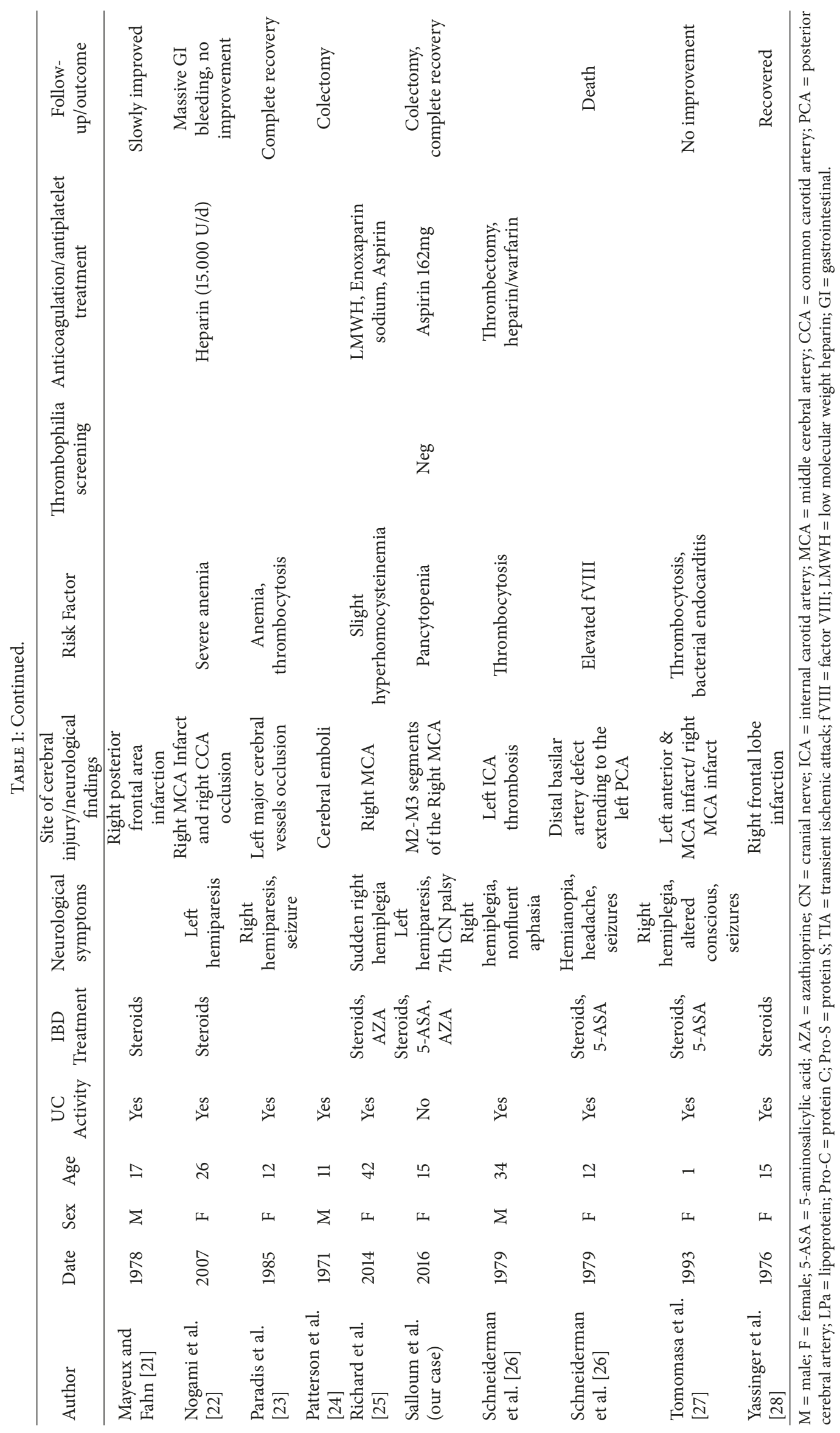


presented as a reference point for the treatment of IBD patients who are complicated by an ischemic cerebral event [38-40].

\section{Conflicts of Interest}

The authors declare that they have no conflicts of interest.

\section{Authors' Contributions}

Mohamad Anas Almidani and Riham Salloum approached the patient, Riham Salloum and Nawras Alhalabi drafted the initial manuscript, and Riham Salloum, Nawras Alhalabi, and Mohamad Anas Almidani revised and wrote the final version of the manuscript and approved publication.

\section{Acknowledgments}

We appreciate the collaboration of the patient and the patient's family; we express gratitude to Dr Anas Jawhar and Dr Tareq Al Saadi for their kind collaboration. In addition, we would like to express our sincere thanks and appreciation to the dean of faculty, Professor Nizar AlDhaher, and the university president, Professor Nazir Ibrahim, the Faculty of Medicine of Syrian Private University Research Group, and We Research Team for their endless encouragement and scientific motivation.

\section{References}

[1] J. T. Danzi, "Extraintestinal manifestations of idiopathic inflammatory bowel disease," JAMA Internal Medicine, vol. 148, no. 2, pp. 297-302, 1988.

[2] R. Kochhar, S. K. Mehta, B. Nagi, V. Bhatia, M. K. Goenka, and A. K. Malik, "Extraintestinal manifestations of idiopathic ulcerative colitis," Indian Journal of Gastroenterology, vol. 10, no. 3, pp. 88-89, 1991.

[3] R. W. Talbot, J. Heppell, R. R. Dozois, and R. W. Beart Jr., "Vascular complications of inflammatory bowel disease," Mayo Clinic Proceedings, vol. 61, no. 2, pp. 140-145, 1986.

[4] F. Houissa, M. Salem, S. Bouzaidi et al., "Cerebral thrombosis in inflammatory bowel disease: a report of four cases," Journal of Crohn's \& Colitis, vol. 5, no. 3, pp. 249-252, 2011.

[5] S. Jain, P. Bhatt, G. Muralikrishna, P. Malhotra, S. Kumari, and S. Varma, "Extensive arterial and venous thrombosis in a patient with ulcerative colitis - a case report," Medscape General Medicine, vol. 7, no. 2, p. 10, 2005.

[6] W. Miehsler, W. Reinisch, E. Valic et al., "Is inflammatory bowel disease an independent and disease specific risk factor for thromboembolism?” Gut, vol. 53, no. 4, pp. 542-548, 2004.

[7] O. Grip, P. J. Svensson, and S. Lindgren, "Inflammatory bowel disease promotes venous thrombosis earlier in life," Scandinavian Journal of Gastroenterology, vol. 35, no. 6, pp. 619-623, 2000.

[8] F. C. Edwards and S. C. Truelove, "Course and prognosis of ulcerative colitis: Part III Complications,” Gut, vol. 5, no. 1, pp. $1-15,1964$.

[9] C. N. Bernstein, J. F. Blanchard, D. S. Houston, and A. Wajda, "The incidence of deep venous thrombosis and pulmonary embolism among patients with inflammatory bowel disease: a population-based cohort study," Thrombosis and Haemostasis, vol. 85, no. 3, pp. 430-434, 2001.

[10] R. S. Calabro, A. Pezzini, G. Gervasi, P. Pollicino, and P. Bramanti, "Recurrent ischemic stroke in a patient with ulcerative colitis and high levels of lipoprotein (a)," Blood Coagulation \& Fibrinolysis: An International Journal in Haemostasis and Thrombosis, vol. 22, no. 6, pp. 549-551, 2011.

[11] G. Casella, C. C. Cortelezzi, D. Marialuisa et al., "Cerebral arterial thrombosis in ulcerative colitis," Case Reports in Gastrointestinal Medicine, vol. 2013, Article ID 679147, 4 pages, 2013.

[12] K. Chetri, U. C. Ghoshal, S. K. Somani et al., "Common carotid artery occlusion causing cerebral infarction in ulcerative colitis," Indian Journal of Gastroenterology: Official Journal of the Indian Society of Gastroenterology, vol. 21, no. 3, pp. 122-123, 2002.

[13] T. Fukuhara, S. Tsuchida, K. Kinugasa, and T. Ohmoto, "A case of pontine lacunar infarction with ulcerative colitis," Clinical Neurology and Neurosurgery, vol. 95, no. 2, pp. 159-162, 1993.

[14] D. Hilton-Jones and C. P. Warlow, "The causes of stroke in the young," Journal of Neurology, vol. 232, no. 3, pp. 137-143, 1985.

[15] P. G. Jorens, C. R. Hermans, I. Haber, M. M. Kockx, J. Vermylen, and G. A. Parizel, "Acquired protein C and S deficiency, inflammatory bowel disease and cerebral arterial thrombosis," Blut, vol. 61, no. 5, pp. 307-310, 1990.

[16] P. G. Jorens, C. R. Delvigne, C. R. Hermans, I. Haber, J. Holvoet, and P. P. De Deyn, "Cerebral arterial thrombosis preceding ulcerative colitis," Stroke, vol. 22, no. 9, pp. 1212-1212, 1991.

[17] D. Joshi, T. Dickel, R. Aga, and G. Smith-Laing, "Stroke in inflammatory bowel disease: a report of two cases and review of the literature," Thrombosis Journal, vol. 6, no. 1, p. 2, 2008.

[18] D. L. Keene, M. A. Matzinger, P. J. Jacob, and P. Humphreys, "Cerebral vascular events associated with ulcerative colitis in children," Pediatric Neurology, vol. 24, no. 3, pp. 238-243, 2001.

[19] M. E. Kelly, J. Dodd, and M. Barry, "Triad of emboli in acute flare of ulcerative colitis," Irish Medical Journal, vol. 107, no. 5, pp. 152-153, 2014.

[20] J. D. Lloyd-Still and L. Tomasi, "Neurovascular and thromboembolic complications of inflammatory bowel disease in childhood," Journal of Pediatric Gastroenterology and Nutrition, vol. 9, no. 4, pp. 461-466, 1989.

[21] R. Mayeux and S. Fahn, "Strokes and ulcerative colitis," Neurology, vol. 28, no. 6, pp. 571-574, 1978.

[22] H. Nogami, T. Iiai, S. Maruyama, T. Tani, and K. Hatakeyama, "Common carotid arterial thrombosis associated with ulcerative colitis," World Journal of Gastroenterology, vol. 13, no. 11, pp. 1755-1757, 2007.

[23] K. Paradis, M. L. Bernstein, and J. W. Adelson, "Thrombosis as a complication of inflammatory bowel disease in children: a report of four cases," Journal of Pediatric Gastroenterology and Nutrition, vol. 4, no. 4, pp. 659-662, 1985.

[24] M. Patterson, L. Castiglioni, and L. Sampson, "Chronic ulcerative colitis beginning in children and teenagers - a review of 43 patients," American Journal of Digestive Diseases, vol. 16, no. 4, pp. 289-297, 1971.

[25] S. Richard, G. Mione, J. Perrin, M. Toussaint-Hacquard, J.-C. Lacour, and X. Ducrocq, "Internal carotid thrombus in patients with inflammatory bowel disease: two cases," World Journal of Gastroenterology, vol. 19, no. 5, pp. 773-775, 2013.

[26] J. H. Schneiderman, J. A. Sharpe, and D. M. C. Sutton, "Cerebral and retinal vascular complications of inflammatory bowel disease," Annals of Neurology, vol. 5, no. 4, pp. 331-337, 1979. 
[27] T. Tomomasa, K. Itoh, A. Matsui et al., "An infant with ulcerative colitis complicated by endocarditis and cerebral infarction," Journal of Pediatric Gastroenterology and Nutrition, vol. 17, no. 3, pp. 323-325, 1993.

[28] S. Yassinger, R. Adelman, D. Cantor, C. H. Halsted, and R. J. Bolt, "Association of inflammatory bowel disease and large vascular lesions," Gastroenterology, vol. 71, no. 5, pp. 844-846, 1976.

[29] J. A. Bargen and N. W. Barker, "Extensive arterial and venous thrombosis complicating chronic ulcerative colitis," JAMA Internal Medicine, vol. 58, no. 1, pp. 17-31, 1936.

[30] A. Wakefield, Z. Cohen, and G. Levy, "Procoagulant activity in gastroenterology," Gut, vol. 31, no. 2, pp. 239-241, 1990.

[31] S. Saibeni, L. Spina, and M. Vecchi, "Exploring the relationships between inflammatory response and coagulation cascade in inflammatory bowel disease," European Review for Medical and Pharmacological Sciences, vol. 8, no. 5, pp. 205-208, 2004.

[32] R. Das, R. K. Vasishta, and A. K. Banerjee, "Aseptic cerebral venous thrombosis associated with idiopathic ulcerative colitis: a report of two cases," Clinical Neurology and Neurosurgery, vol. 98, no. 2, pp. 179-182, 1996.

[33] A. Lam, I. T. Borda, M. J. Inwood, and S. Thomson, "Coagulation studies in ulcerative colitis and Crohn's disease," Gastroenterology, vol. 68, no. 2, pp. 245-251, 1975.

[34] D. A. Novotny, R. J. Rubin, F. A. Slezak, and J. A. Porter, "Arterial thromboembolic complications of inflammatory bowel disease - report of three cases," Diseases of the Colon \& Rectum, vol. 35, no. 2, pp. 193-196, 1992.

[35] A. H. Katsanos, M. Kosmidou, S. Giannopoulos et al., "Cerebral arterial infarction in inflammatory bowel diseases," European Journal of Internal Medicine, vol. 25, no. 1, pp. 37-44, 2014.

[36] V. Hadda, B. D. Pandey, R. Gupta, and A. Goel, "Azathioprine induced pancytopenia: a serious complication," Journal of Postgraduate Medicine, vol. 55, no. 2, pp. 139-140, 2009.

[37] I. E. Koutroubakis, "Therapy insight: Vascular complications in patients with inflammatory bowel disease," Nature Clinical Practice Gastroenterology \& Hepatology, vol. 2, no. 6, pp. 266272, 2005.

[38] B. Brent Simmons, A. Yeo, and K. Fung, "Current guidelines on antiplatelet agents for secondary prevention of noncardiogenic stroke: an evidence-based review," Postgraduate Medical Journal, vol. 122, no. 2, pp. 49-53, 2010.

[39] E. C. Jauch, J. L. Saver, H. P. Adams et al., "Guidelines for the early management of patients with acute ischemic stroke: a guideline for healthcare professionals from the American Heart Association/American Stroke Association," Stroke, vol. 44, no. 3, pp. 870-947, 2013.

[40] The European Stroke Organisation (ESO) Executive Committee and the ESO Writing Committee, "Guidelines for management of ischaemic stroke and transient ischaemic attack 2008," Cerebrovascular Disease, vol. 25, pp. 457-507, 2008. 


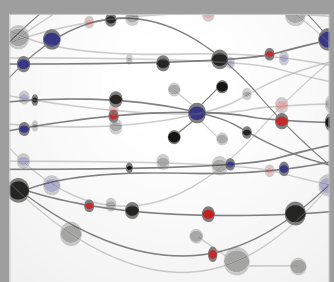

The Scientific World Journal
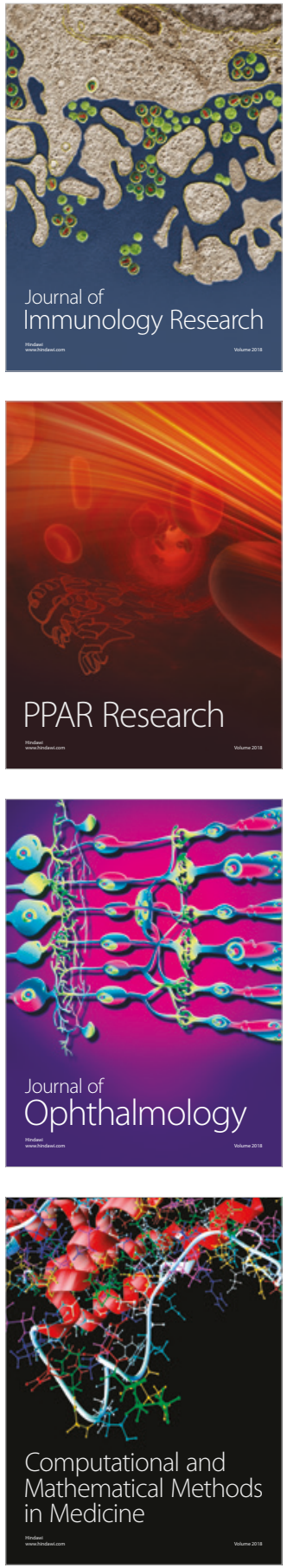

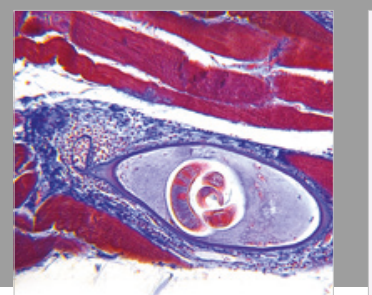

Gastroenterology Research and Practice

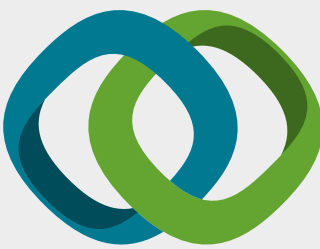

\section{Hindawi}

Submit your manuscripts at

www.hindawi.com
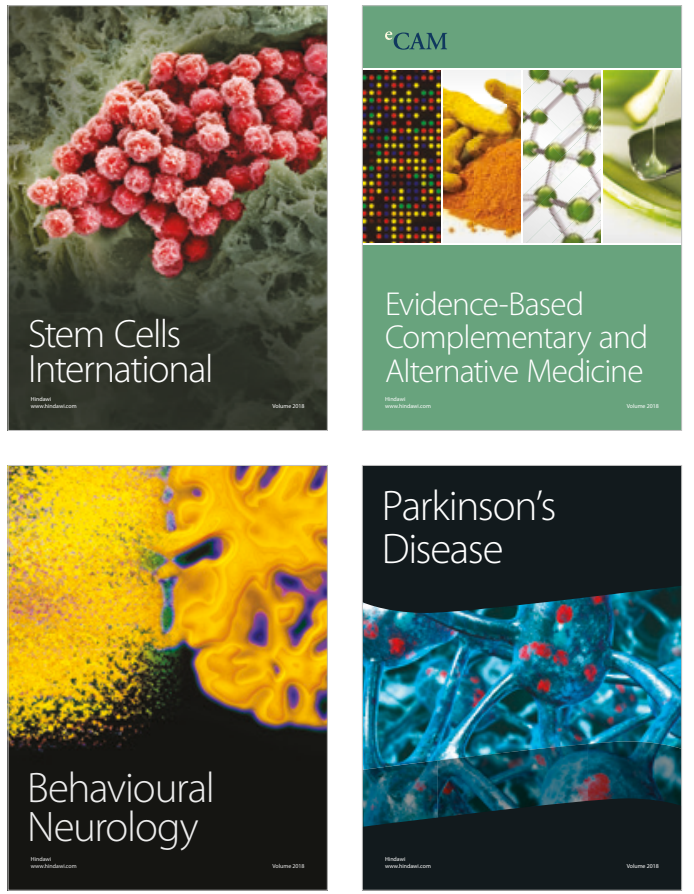

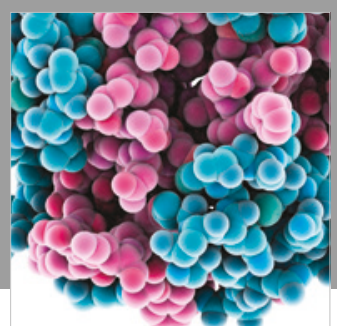

ournal of

Diabetes Research

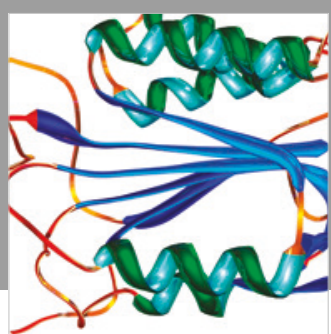

Disease Markers
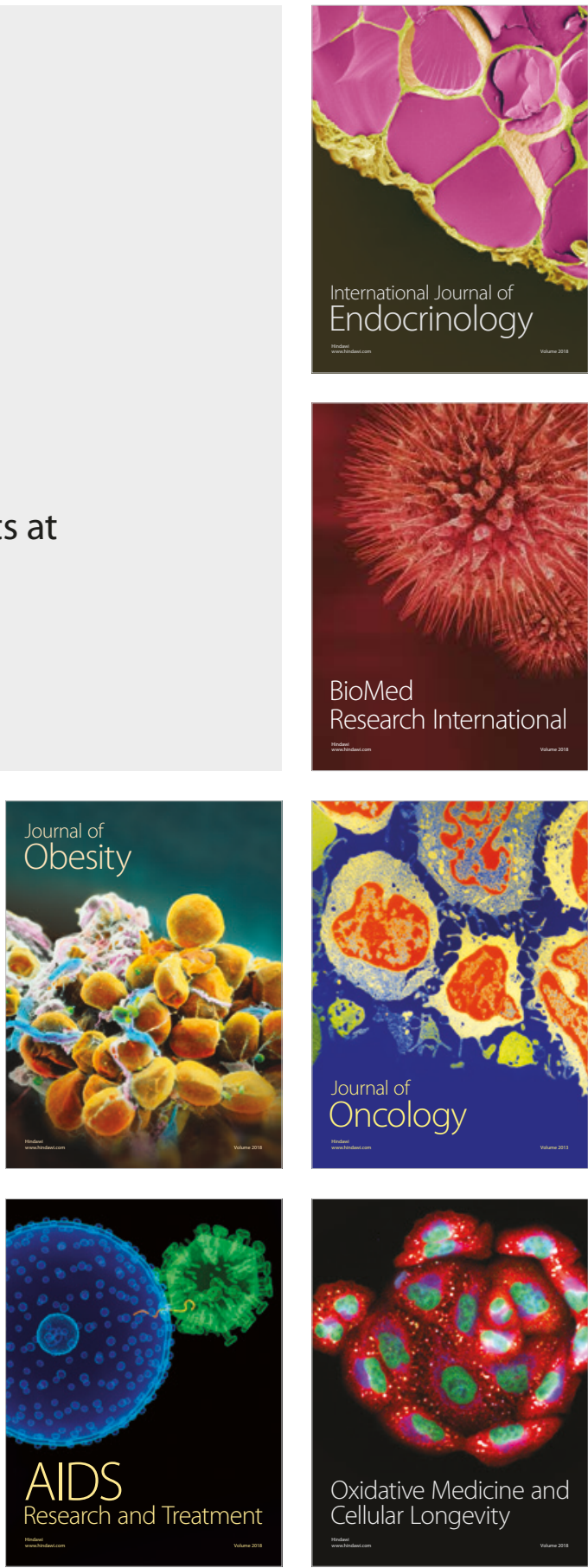